\title{
La sorpresa y la experiencia: historia del presente en la prensa
}

\author{
Dra. Gema Martínez de Espronceda Sazatornil *
}

\section{RESUMEN \\ La historia del presente}

(Zeitgeschichte) fue reivindicada, ya en 1953 por H. Rothfels, como "la de la generación que la habia vivido

(Mitlebenden)", y más como una categoría que como un periodo. En la

- sociedad de la información- la prensa no sólo es una acumulación de datos o conocimientos disponibles para el lector. Ya que la construcción de la realidad cotidiana que supone el trabajo periodístico, potencia dos dimensiones, que cierta historia y especialmente la historia del tiempo presente, ha reivindicado desde finales de los años sesenta, frente al dogmatismo de una historia que sacrificaba al sujeto (la experiencia) y prescindia de la contingencia (la sopresa). Todo lo dicho se comprueba en este estudio del tratamiento que la prensa europea dio al (inesperado) proceso que produjo la reunificación alemana.

\begin{abstract}
Contemporary history

(Zeitgeschichte) was vindicated, as early as 1953 by H. Rothfels, as "that of the generation had lived it (Mitlebenden)", and more as a category than as a period. In the "news society" the press is not only an accumulation of data or available knowledge for the reader. Since the construction of everyday reality that makes up the journalistic work, promotes two dimensions, that certain history and especially the history of the present time, has vindicated since the end of the sixties, in contrast to the dogmatism of a history that sacrificed the subject (the experience) and did without the contingency (the surprise). All this is proved in this study, of the treatment that the European press gave to the (unexpected) process that produced the German reunification.
\end{abstract}

\footnotetext{
* Prof. Titular H." Contemporáneat. Medios de Comunicación. Dpto. de H. Moderna y Contemporánea. Univ. Zaragoza.
} 
PALABRAS CLAVE

Opinión pública, Historia de Alemania, 1989-1990, Prensa análisis de

contenidos.
ABSTRACT

Public opinion, German History, 1989-1990, Analysis of Newspaper

Content.

En una de sus novelas Virginia Wolff escribía que «si no existen ni los comienzos ni los finales, entonces no existen los relatos". Pero, la Historia del Tiempo Presente (HTP) en la medida en que más merece su nombre, es decir, en la medida en que trata de la historia inmediata y no estudia procesos concluidos como el nacionalsocialismo o el régimen de Vichy, se ve obligada a hablar de historias cuyo fin desconoce ${ }^{1}$.

La historia del tiempo presente, dice un filósofo, se ve confrontada más a menudo con los "événementes-charnières", que le sirven de punto de arranque, como 1945, que con los "événementes-clôtures", que significan el fin de un desarrollo, lo que le obliga a dibujar curvas de las que solo conoce el comienzo o la mitad..." ${ }^{2}$. Y a menudo cuando se presenta un acontecimiento que cierra, y que permite después reinterpretar el pasado reciente, se presenta de pronto, «nocturnamente, como un fenómeno de la naturaleza" " ${ }^{3}$ "columnas de repente desvanecidas", que dijo el poeta, aunque aquí no se trate de columnas, sino de un muro, el muro de Berlín y todo lo que vino después.

En estos casos, el periodismo, "la única forma narrativa en la que es posible omitir el final" como dice el columnista americano Jim Hoagland ${ }^{4}$,

\footnotetext{
1 "A la difference des autres historiens, ils (los del Tiempo Presente) ne connaissent pas la fin de I'histoire qu'ils ecrivent", dice, por citar un autor entre muchos, Dominique Schnapper en "Le temps présent entre historire et sociologie", en Ecrire /'histoire du temps présent. En hommage à François Bédarida. Paris, 1993, 49-52, p. 51.

2 P. Ricoeur, "Remarques d'un philosophe", en Ecrire... o.cit., p.35-41, p.38-39. Para el filosofo francés esta circunstancia obliga a cierta dosis de previsión o anticipación a fin de dar sentido a los hechos que se narran, lo que no constituye tanto una objeción capital contra la historia del presente más inmediato, como una de sus características. Para otro filósofo, anglosajón y neopositivista, la ausencia de un final es decisiva: "la frase de Pierce de que el "futuro está abierto" solo significa que nadie ha escrito (ni puede escribir) la historia del presente", A.C. DANTO, Historia y narración, ed. Fina Birulés, Barcelona, 1989, p.155. A lo mejor Danto tiene razón, pero de hecho la historia del presente sigue escribiéndose.

3 Así calificó la caida del Muro de Berlin el Frankfurter Allgemeine Zeitung für Deutschland (FAZ de ahora en adelante) en su editorial del 11 de noviembre.

4 Citado en Furio Colombo, Ultime notizie sul giornalismo, Manuale di giornalismo internazionale. Roma, 1995, p.78.
} 
lejos de caer en esa tentación (como sucede a veces, aunque esto es otro tema), coincide por un tiempo con el historiador en su función de cronista en tiempo real de lo que está aconteciendo. La prensa, entonces, puede significar algo más que una acumulación de datos disponibles, pues en jornadas como las que nos van a ocupar, la construcción de la realidad cotidiana que supone siempre el trabajo periodístico ${ }^{5}$, potencia dos dimensiones muy privilegiadas por la reciente historiografía: la del sujeto (la experiencia) y la de la contingencia (la sorpresa). Así se explica que los defensores de "un giro hermenéutico y simbólico", y hasta "narrativo", de la historia social no hayan vacilado en recurrir al relato de «las rupturas en Europa central en 1989" como "muestra evidente" de la importancia de las "percepciones y praxis de los sujetos" y de lo imprevisto ${ }^{6}$.

Efectivamente, incluso aquella prensa que, en su intento de racionalización, insistía al principio en que no había que exaltarse, "pues los datos no han cambiado, tan solo había cambiado el estado de ánimo de las personas en el país", como decía el reputado periodista Theo Sommer en Die Zeit el 22 de septiembre, termina por reconocer que "la espontaneidad" y "la explosión de sentimientos» habian desencadenado algo que nadie esperaba, como concluía Roderic Reinfenrath en el Frankfurter Rundschau del 11 de noviembre ${ }^{7}$. Y además y sobre todo se constituía una gran sorpresa. Nadie, dice un periodista alemán evocando aquellos años, ningún político, ningún periodista, ningún experto en la Unión Soviética, ningún escritor, podía suponer lo que iba a pasar, y al final toda la prensa terminó siendo sorprendida por la rapidez de la reunificación ${ }^{8}$.

5 De manera análoga, aunque no idéntica, a como el historiador, el periodista no se limita a reflejar pasivamente la realidad sino, "que la construye en la medida en que produce la noticia", frase de Gaye Tuchman, citado en G. Martínez de Espronceda, "La noticia también es fuente", en Jornadas sobre Prensa y Sociedad, Logroño, 1991, p.139-144.

${ }_{6}$ Cosa que sucedió especialmente en Alemania, donde los suplementos culturales de la prensa conservadora ajustaron sus cuentas con la historia social, aduciendo triunfalmente un proceso que, según ellos, solo podia ser "contado", pero no deducido o "explicado" desde las estructuras, sino "comprendido" o "interpretado». Los entrecomillados son del trabajo de Ute Daniel, "Quo vadis Sozialgeschichte? Plädoyer für eine hermeneutische Wende", en W. Schulze, ed. Sozialgeschichte, Alltagsgeschichte, Mikro-historie, Göttingen, 1994, p. 54-65, p. 60. Aunque no es tema de este trabajo, interesa indicar que la "historia social estructural» recogió con presteza el guante: J. Kocka, "Überrraschung und Erklärung. Was die Ümbruche von 1989/90 für die Gesellschaftgeschichte bedeuten können?", en M. Hettling ed. Was ist Gessellschafsgeschichte?, München, 1991, p.11-21, y más recientemente en Vereinigungskrise, Göttingen, 1995.

Theo SOMMER, "Kleine Schritte oder grosse Luftsprünge?", Die Zeit, 22.9.1989; R. Reifenrath, «Leben ohne Mauer», Frankfurter Rundschau, 11.11.1989.

8 Son frases de Karl-Heinz JANSSEN, que fue durante muchos años redactor político de Die Zeit, en Die Zeit in der Zeit, Berlin, 1995, p.317. 
Para calibrar lo inesperado de los hechos, la dimensión de la sorpresa, puede recordarse, como hacia el FAZ a finales del verano del 89 , que todavía hacía algunos meses el mismo canciller Kohl, no solamente ignoraba la reunificación, sino que no creía que la "deutsche Frage", la cuestión alemana, figurase en la agenda de la Weltpolitik en absoluto ${ }^{9}$. Pero, lo más significativo es que tampoco figuraba realmente en la agenda de la propia política alemana, de la opinión pública alemana. Efectivamente, a la altura del año crucial que nos ocupa, hacía ya muchos decenios que la Republica Federal había superado aquella sensación de provisionalidad, que todavia mediados los cincuenta había inspirado al conocido periodista Erich Kuby la imagen de la patria como setenta millones de alemanes en dos salas de espera del fantasmagórico tren de una posible reunificación ${ }^{10}$. La sociedad alemana había terminado acomodándose a la existencia de dos estados. A ello había contribuido la política exterior de Adenauer y el éxito de la política económica de Erhard, el llamado "Wirtschaftswunder» 11.

El tema de la unidad terminó acantonándose en el rito del "Tag der Deutsche Einheit" cada 17 de junio, "en los discursos dominicales de los políticos o en las filípicas de los apóstoles intelectuales de la moral». Una situación, como sigue diciendo un publicista de aquellos años, que "preservaba el alma del ciudadano federal del espanto de la reunificación y le permitia, al mismo tiempo, la placidez de soñar a veces con algo que de todos modos no iba a llegar» ${ }^{12}$. De parecida manera, una semana antes de la erección del muro de Berlín, el 13 de agosto de 1961, la conocida periodista Marion Gräfin Dönhoff hablaba del "deutsche Michel», estereotipo del alemán medio, «instalado cómodamente con muebles de estilo, enanos de jardín y Volkswagen", y cuyo tranquilo sueño no alteraba ni un ápice lo que parecía venirse encima ${ }^{13}$. Aunque los porcentajes de los alemanes occidentales que se

\footnotetext{
9 "Die deutsche Frage ist gestellt" en FAZ 11.8.1989. Hasta que punto Kohl decia una verdad, sobre todo por lo que hacia a sus vecinos, puede comprobarse en el trabajo de Peter H. Merkl, German Unification in the European context, Pennsylvania, 1993, especialmente p. 303 y ss.

10 Erich KuBY, Das ist des deutschen Vaterland: 70 millionen in zwei Wartesälen, el libro alcanzó una gran difusión en su segunda edición de bolsillo, Hamburg, 1959.

1 En un ponderado trabajo sobre la politica exterior de la república federal, Waldemar Besson concluye que, para Adenauer, la "reunificación no era su objetivo principal, en el mejor de los casos era una cuestión secundaria sobre cuyas modalidades, en todo caso, nunca se hablaba" en Die Aussenpolitik der Bundesrepublik, München, 1979, p.152. Su sucesor Ludwig Erhard cuando lo hacía, se refugiaba en una «metafísica histórica» que le llevaba a "confiar fervorosamente (voller Inbrust) en el futuro" sin más, tal como manifestaba en el día de la unidad alemana del 17 de junio de 1964 (en W. Euchner, “Der permanenten Selbstbetrug. Zur Deutschlandpolitik der Bundesregierung", en Politik ohne Vernuft, Hamburg, 1965, p.28-47, p.41.

12 Hermann Glaser, Kulturgeschichte der Bundesrepublik Deutschland, II, München, 1986, p.44.

Marion GRAFIN DONHOFF, "Des deutschen Michels Schlat...sind wir vorbeiretet auf die Dinge. die da kommen? ", en Die Zeit, 4.8.1961
} 
declaraban (platónicamente) partidarios de la reunificación siempre fueron relativamente altos, la resignación (o el acomodo) se traduce en los correspondientes al "reality test", de esta manera en 1968 todavia un $13 \%$ juzgaba la reunificación previsible en algún futuro, pero en 1984 ya solo era un $5 \%$, y en 1987 la cifra se había reducido a un 3\%, año en el cual un 6\% la juzgaba algo ilusorio ("Wunschvorstellung") ${ }^{14}$.

Por su parte los intelectuales alemanes, con independencia de su valoración de la historia alemana ${ }^{15}$, coinciden en sus diagnósticos del estado de la opinión. Así el historiador Thomas Nipperdey concluía en 1985: "el tema de la unidad estatal de Alemania parece hoy un problema desvanecido, un tema de la vieja generación, de los marginales, de los profesionales del partido Panalemán, de la teórica política o bien un tema de los neutralistas de izquierda o derecha", "aunque el historiador no es un profeta", "es un hecho que quizá Alemania no vaya a ser jamas una nación unida"... ${ }^{16}$. En una reciente historia de la República Federal se afirmaba, incluso, que 1989 fue un año en el que menos que nunca hasta entonces, los alemanes esperaban la unidad. Dos hechos simbólicos lo mostrarian: el 1 de agosto del 89, tres meses antes de la caída del Muro, Die Welt, el diario apóstol de la unidad, hasta entonces bajo la dirección del fallecido Springer, abandona las comillas entre las que encerraba la mención de la DDR, la República Democrática Alemana, tras haberse resistido hasta el final a dejarla de llamarla "Zone" o SBZ, zona de ocupación soviética; y el Museo de Historia proyectado por el canciller Kohl albergaría la historia alemana en su sede de Berlín solo hasta 1945, a partir

1. MERKL, o.cit. p.120-124, donde se analizan todas las encuestas de estos años, distinguiendo además por grupos de edad, concluyendo: "before 1989, reunification was disembodied issue of nearly universal popularity, high ideological symbolism, and no policy content whatsoever except in the transmuted form of Willy Brandt"s Ostpolitik measures of détente». De ahi el calificativo "the great Surprise" que este autor utiliza para designar a los acontecimientos de 1989.

Desde fecha, muy temprana se acepta por algunos la división de Alemania, no solo por considerar la unidad estatal como un mero episodio en la historia de la "Kulturnation", sino además como consecuencia de las culpas de la época nacionalsocialista, "Auschwitz ha provocado la prescripción del derecho a estar unidos", a lo que se suman naturalmente los requisitos del equilibrio de las grandes potencias, Estados Unidos y la Unión Soviética. Sobre las polémicas de los años cincuenta y sesenta ver Glaser, o.cit. p. 38-48; en los ochenta Habermas o Günter Grass sostuvieron posturas parecidas y las mantuvieron incluso en los noventa. H.U.Wehier, uno de los representantes de la "historia social», recuperaba parte de esta argumentación unas semanas antes de la caida del muro, para negar la posibilidad razonable de la reunificación alemana, en el artículo titulado "Deutsche Frage und europäische Antwort», Frankfurter Rundschau, 13.10.1989.

16 T. NIPPERDEY "Die Deutsche Einheit in historischer Perspektive" en Nachdenken über die deutsche Geschichte, München, 1986, p. 249-263, p. 261. Todavia en 1989 un historiador conservador como Karl Dietrich Erdmann pensaba en una normalización de la división siguiendo el modelo austriaco: Die Spur Österreichs in der deutschen Geschichte, Zurich, 1989, p. 11. 
de aquella fecha la historia, esta vez solo de la República Federal, se instalaría en la sede de Bonn ${ }^{17}$. Si bien no es cierto, tal como se ha afirmado a veces después de 1990, que hubiesen desaparecido por completo del mercado editorial los defensores de la posibilidad de una reunificación, sin embargo si lo es que sus tesis eran ignoradas o juzgadas molestas y marginales ${ }^{18}$.

Había, además, motivos políticos más que suficientes para que la aceptación de la existencia de dos estados alemanes se afianzase todavía más en la opinión pública durante los años ochenta. Tras el reconocimiento que había supuesto su viaje a Bonn, el dictador germano oriental Honecker veía multiplicarse sus logros diplomáticos: recibido por los monarcas belgas en octubre de 1987, lo era también por el ministro francés en enero de 1988 y por el gobierno y la familia real española en octubre del mismo año. Evidentemente, y a la vista de lo que vino después, era solo una «ilusión de éxito", pero una ilusión en la que también habian creído los habitantes y los políticos de la República Federal ${ }^{19}$. De esta manera, a finales de 1988 el ministro de Asuntos Exteriores, el liberal Genscher, anticipaba el contenido del mensaje de año nuevo de Kohl en un artículo publicado en Die Zeit, donde, respetando las clausulas de estilo, a la unidad alemana se anteponía la unidad europea, concibiéndola ademas como fruto de una cooperación entre dos estados alemanes independientes ${ }^{20}$. Unos meses antes, Marion Gräfin Dönhof se había expresado más crudamente: «nuestro objetivo no debe ser la reunificación, sino la aproximación entre este y oeste» 21 . Aunque no toda la prensa había renunciado a la retórica de la unidad, pensemos no solo en la Boulevard Presse, los tabloides tipo Bild, sino además en Die Welt y FAZ, nadie ofrecia alternativas creibles a la Ostpolitik inaugurada por los socialdemócratas, conducente, a través de la distensión y los "pequeños pasos", a la convivencia de los dos estados, con la reunificación

17 Dietrich Tränhardt, Geschichte der Bundesrepublik Deutschland, Frankfurt, 1996, p.310-311.

18 La lista de publicaciones (extravagantes) de los ochenta en Träumhardt, o.cit. p.369, confirma lo dicho.

19 La expresión entrecomillada de A. James McAdams. German divided. From the Wall to Reunification, Princenton (J:), 1993, p. 177. Hasta junio de 1989 hubo contactos regulares entre los dos estados, incluso entre la Volksarmee y la Bundeswehr, propugnando nuevas tareas, como una «seguridad ecológica común», ver Thomas Ammer, «Politische Kontakte Bundesrepublik-DDR im ersten Halbjahr 1989", en Deutschland Archiv, sep. 1989, p. 1019-1027.

20 "Ein Plan für das ganze Europa», Die Zeit, 20.10.1988.

21 "Ein Dach für ganz Europa», Die Zeit, 19.4.1988. El año anterior en el mismo diario, y precisamente con motivo del Dia de la Unidad alemana, Theo SoMMER había sido todavía más descarnado: hay que escoger, decia, entre el sueño de la unidad y la realidad de una comunidad europea, exigiendo que, volviendo la espalda incluso a lo dispuesto en la misma Constitución, "se creasen circunstancias en las que no volviese a plantearse la cuestión de la reunificación" (“Die Einheit gegen Freiheit tauschen. Wir müssen uns ehrlich machen», en Die Zeit, 18.6.1987). 
en el mejor de los casos a largo plazo como producto subsidiario de la unificación europea. Helmut Schmidt, por ejemplo, con motivo del viaje de Honecker a la RFA la situó en el horizonte del siglo XXI, cosa que seguia sosteniendo como editor de Die Zeit todavia en septiembre de $1989^{22}$.

Sobre este fondo de opinión comienzan a registrarse en los media de Alemania occidental, primero los movimientos organizados de protesta en el interior de la DDR, por el falseamiento de las elecciones municipales de mayo de 1989 ("Bürgerrechetsgruppen») y, después, la espectacularidad en el exterior de un éxodo vacacional que se transformó en un auténtico "Massenflucht", huida en masa. Esta especie de "transmigración", decía el Frankfurter Rundschau, "no se diferenciaba en su dramatismo y sus innumerables tragedias humanas" de los éxodos de 1945, los sucesos de 1953 o de la emigración en masa que había provocado en 1961 la construcción del Muro de Berlín, pero ahora se realizaba, no solo, en un contexto internacional muy distinto, aunque cargado de incógnitas, sino además, "ante las cámaras de la televisión y amplificado por los media de toda la opinión pública mundial» ${ }^{23}$.

Cada periódico pudo tener su propia idea de las posibilidades de reforma en cada momento del régimen de la DDR, sometido a la doble presión de la emigración y de la organización de la disidencia interna; pudo enjuiciar de distintas maneras las reacciones de los distintos partidos políticos e incluso valorar también de manera distinta el condicionamiento internacional de la cuestión alemana. Pero lo que aquí nos interesa es la coincidencia que, por encima de todas estas diferencias, se registró en los media estudiados: primero, en que se trataba de un proceso autónomo que respondía a la experiencia y a la expectativa de los actores, segundo, que incluso para los más optimistas y en fechas que retrospectivamente se nos aparecen como definitivas, todavía se desconfíaba de que la reunificación fuese algo de un día para otro ${ }^{24}$.

\footnotetext{
22 "La cuestión alemana se resolverá solo en el próximo siglo", concluia en "Brüderlichkeitauch im eigenen Interesse", Die Zeit, 15.9.1989.

23 Los entrecomillados son del editorial del Frankfurter Rundschau del 5 de octubre de 1989. "Gesamtdeutsche Ohmancht" de E. MöBITz.

24 Hemos escogido tres publicaciones de calidad y de difusión considerable, representativas de las posturas de las tres corrientes políticas, más que de partidos stricto sensu, frente a la cuestión alemana y la reunificación: los diarios Frankfurter Allgemeine Zeitung für Deutschland, conservador de orientación demócrata cristiana, y Frankfurter Rundschau, socialdemócrata, y el semanario Die Zeit, liberal. Las tres publicaciones disponen desde un principio de enviados especiales tanto en embajadas como en centros de acogida de refugiados, y más tarde de corresponsales en los principales focos de agitación política y social de la DDR. Hemos prescindido del análisis de las crónicas, reportajes y entrevistas que reflejan la experiencia y las vicisitudes humanas de refugiados y
} 
El primer factor sorpresa lo representó precisamente la espontaneidad y dimensiones del movimiento de huida hacia la República Federal y que contrastaba con la desorientación de los políticos: "Para la perplejidad con que reacciona, no solo Berlín oriental, sino también Bonn, frente al éxodo de los refugiados habria una posible disculpa. Nadie podia prever razonablemente que tantos jóvenes ciudadanos de la DDR, educados bajo la hegemonía del SED, llegarian al grado de desesperación de buscar su salvación en la huida», decía el Frankfurter Rundschau. Por su parte el FAZ, por boca de su corresponsal en Bonn, declaraba que el gobierno carecía de ideas claras, y actuaba a remolque de un movimiento que no obraba mas que al dictado de sus sentimientos, «en Bonn todo está bajo la sombra de la huida en masa" ${ }^{25}$. Podrian multiplicarse las editoriales que denunciaban la "Konzeptlosigkeit», la falta de ideas, frente a lo que estaba sucediendo. Pero había algo más, para el FAZ, por ejemplo, "los alemanes de uno de los medio estados han tomado sencillamente la palabra, $y$ han dado a los que viven en el otro medio estado una lección de madurez histórica ("Geschichtsmächtigkeit») que esperamos no se olvide fácilmente» ${ }^{26}$. Con esto el diario conservador aludía al otro tema, lo que no dejaba de ser algo abusivo, pues ni las primeras, y todavia reducidas manifestaciones en Leipzig, ni los primeros turistas de la DDR que se hacen refugiados a través de Hungría, significaban otra cosa que la exigencia de reformas de régimen en el primer caso, y el deseo de vivir mejor en el segundo ${ }^{27}$. Pero era inevitable que la nueva situación provocase la reactivación de la retórica de la unidad, tal como se manifiesta en el FAZ, por no hablar de Die Welt y su grupo editorial. Incluso en Die Zeit, Willy Brandt, en conversación con el corresponsal en Bonn Günter Hofmann, llegaba a preguntarse proféticamente por estas fechas cómo reaccionaria la República Federal cuando en Leipzig varios cientos de miles clamasen por la reunificación. Pero también

manifestantes, ya que alargaria mucho este trabajo, contentándonos con algunas referencias de paso. En todo caso, no deja de ser aplicable a las tres publicaciones, salvando las diferencias de estilo e ideologia, lo que un periodista de Die Zeit dice de la suya: la "dicción" de editoriales y artículos de fondo intenta mantener un tono más bien frío y racional, reservando las emociones (patrióticas, políticas o humanas) para los reportajes de las páginas interiores o de los suplementos especiales (C-H. JANSSEN, o.cit., p.305). Aunque también aquí un estudio más detallado que el nuestro podria apreciar, según los momentos, desplazamientos y titulares muy significativos, aunque sin llegar al descarado «slanting" practicado por la Boulevard Presse, o prensa amarilla.

25. Editorial del Frankfurter Rundschau d el 5 de octubre de 1989 citado en nota 23; la crónica de Bonn de Claus Gennrich intitulada como el entrecomillado del texto, "In Bonn steht alles im Schatten der Massenflucht", FAZ, 4.10.1989. La investigación reciente confirma esta impresión de los diarios, McAdams, o.cit., p.204 y ss; Merkl, o.cit., p.129 y ss.

26 "Geschichtliche Aufbruch", editorial del 6.10.1989.

27 En ellos coinciden tanto McAdams, 0.cit., p.185 y ss., y Staritz, Dietrich, Geschichte der DDR, Frankfurt, 1996., pp. 346 y ss. 
en este periódico Theo Sommer, en un largo artículo publicado tras la visita de Gorbachov en junio de 1989, con el pomposo título de "Quo vadis Germania? ", escribía la frase que tanto habría de echársele en cara después, pero que no dejaba de representar parte de la opinión: "quien hoy saque del armario el esqueleto de la unidad alemana, solo puede producir angustia y espanto a los otros» ${ }^{28}$. Era una realidad, sin embargo, que «tras la huida en masa de la DDR los políticos alemanes hablan de manera muy distinta sobre Alemania, sobre la unidad alemana y sobre la reunificación", y el FAZ concluía el 10 de Octubre que «la nación alemana no puede sentirse más unida en conciencia y sentimientos de lo que está ahora" ${ }^{29}$. Contra este triunfalismo reaccionaba en el otro extremo el Frankfurter Rundschau, advirtiendo contra los que precipitadamente, los "schnelldenker", suponian la unificación en puertas y tachaba de enemigos de la unidad alemana a todos los que no compartían su opinión ${ }^{30}$.

Pero, a excepción de la prensa popular y ciertos editoriales de Die Welt, todos guardaron prudente reserva en los plazos de cumplimiento de su cábalas sobre el destino de Alemania. Cuando, por ejemplo, el FAZ el día de la caída de Honecker proclamase que «una palabra está de nuevo de moda", la de reunificación, advertía enseguida del peligro de una rehabilitación del concepto, por un lado tan rápida que se agotase en una coyuntura política corta, y por otro tan apasionada que despertara la esperanza de una pronta realización, cuando se trataba de un largo proceso ${ }^{31}$.

Y de pronto, el 9 de noviembre por la tarde, el jefe del SED de Berlín Günter Schabowski, anunciaba a la prensa que al día siguiente entraria en vigor la nueva ley que autorizaba el libre desplazamiento a la RFA, «few decisions of greater historical consequence have been announced with such nonchalance " ${ }^{32}$. Podríamos creer que la caida del Muro, y los tres días de confraternización jubilosa a lo largo de toda la frontera de la antigua zona, fueron ya percibidos claramente como la reunificación en ciernes, y hay testigos que hoy se admiran de no haberlo entonces visto asi ${ }^{33}$.

28 Die ZEIT, 23.06.1989.

29 «Man spricht wieder von Einheit", artículo editorial de J.G. Reissmüller, en 10.10.1989.

30 Editorial "Ein Fest im Schatten" de Werner Holzer, 7.10.1989, el autor en todo caso pensaba al decir esto más que en los editoriales del FAZ que, como veremos, siempre guardaba una prudente reserva sobre los plazos, en el desatado nacionalismo de Die Welt y de la prensa situada más a la derecha.

3. "Ein Wort kommt in Mode" de Friedrich K. FrommE, 17.10,1989.

32 MCADAMS, o.cit., p.3.

33 Karl-Heinz JANSSEN, o.cit., que llega a decir «harán falta todavia muchas investigaciones científicas y también algunos estudios psicológicos para explicar las causas del déficit de los media de Alemania occidental en su percepción de lo que sucedió entonces", p. 318. Aunque tienen 
Pero entonces solo los media más irresponsables y sensacionalistas no dudaron en lanzarse a cantar con fanfarrias el himno de la unidad de todos los alemanes ${ }^{34}$. La prensa seria reaccionó con más prudencia y más acorde con el estado de animo mayoritario en la opinión germanooccidental como mostraron las encuestas ${ }^{35}$. A la mañana siguiente del día 10 de noviembre, el Frankfurter Rundschau lograba editorializar sin utilizar ni una sola vez la palabra reunificación y ni siquiera la palabra unidad. Hubo, en cambio, un canto a la historia hecha desde abajo, a la experiencia de los actores: una explosión de sentimiento (Gefühlausbrüche) que logró con su espontaneidad y de un golpe lo que, otras veces, se hacía friamente a espaldas de la gente, "en trabajosos y milimetrados trabajos de comisiones oficiales y a través de compromisos diplomáticos". Se reconocía, pues, la autonomía y el poder del sentimiento, pero se limitaba su alcance, como hizo el alcalde socialista de Berlín, Momper, que dias después declararía al Spiegel que la noche del 9 al 10 no había sido la fiesta de la reunificación (Wiedervereinigung), sino la fiesta del reencuentro (Wiedersehen), lo que se habría logrado era el derecho a «moverse libremente". Le tocaría ahora a la DDR "el trabajo de Sisifo de comenzar de nuevo sus reformas" ${ }^{36}$.

Pero, quizá la mejor muestra de la escasa medida en que la prensa percibió la real importancia de lo que sucedía en la noche del 9 al 10 de noviembre, fuera la reacción del FAZ, un periódico tan propenso desde siempre a reclamar una política unitaria más dinámica. EI FAZ pareció no creerse del todo la realidad tal como la sentían los berlineses, de hecho su

mayor disculpa, tampoco la prensa europea percibió el plano inclinado que iba a llevar de la caída del Muro a la reunificación tan solo en meses. De todos modos, en el caso francés el temor a la potencia económica de una Alemania reunificada le hace preguntarse a Le Monde, en un editorial titulado "Effondrement" del 11 de noviembre, si "la reunification politique "de facto" ne se profil-telle pas à l'horizon". A finales del mismo mes el diario francés, si bien califica de "processus inevitable" to que esta sucediendo, comienza proclamando que «la question de reunification allemande n'est peut-ètre d'actualité, y se consuela pensando que "M. Kohl a en la prudence de ne fixer aucun calendrier et de ne pas prejuger de la forme juridique d'une eventuelle unité de l'Allemagne", hablando todavia de "une RDA en train de changer de nature" (30.11.1989), ver G MARIINEZ DE ESPRONCEDA, "Lo imprevisto inevitable: la unificación alemana en la prensa francesa", en Historia del Tiempo presente. Teoria y metodologia. ICE- Universidad de Extremadura, 1998.

34 Desgraciadamente no disponemos de espacio para estudiar el mensaje nacionalista y demagógico que, por ejemplo, transmitian textos y maquetación de publicaciones como el Bild de la casa Springer.

35 A finales de noviembre la agencia Emnid constataba que solo un $27 \%$ de los alemanes occidentales creía posible la reunificación, un $44 \%$ esperaba que las relaciones entre las dos Alemanias mejorasen cualitativamente hasta ser análogas a las existentes entre la BRD y Austria, y in $25 \%$ seguia creyendo que, por muchos progresos que se hiciesen, los dos estados alemanes permanecerian independientes y cada uno integrado en un bloque distinto (datos según Der Spiegel, 20.11.1989. pp. 16-17).

"sti "Leben ohne Mauer" de Roderich ReifenRath, Frankfurter Rundschau, 11.11.1989. La entrevista de Momper en Der Spiegel, 13.11.1989. 
editorial se planteaba una pregunta en su título: «El muro.. ¿un monumento?", y los interrogantes se repetían en el texto: "¿se trata de una decisión irreversible o de una dosis de homeopatía política para estabilizar al régimen en su forma dictatorial?». En este contexto al periódico «la palabra reunificación le parece todavía precipitada" (voreilig), y si de verdad se ha iniciado un proceso que conduzca a la unidad "el camino todavía es muy largo", y la frase final de consuelo parece alejarlo más: «einmal aber kommt der Tag"... 37. Die Zeit, como semanario, dispuso de más tiempo para elaborar sus reflexiones, ya que el día 10 se encontraba desde la víspera en los kioskos. Y en aquel día, paradójicamente en primera, un largo artículo de su editor, el antiguo canciller socialista, Helmut Schmidt, emplazaba la reunificación dentro de los próximos veinte años, y en el interior un artículo significativamente titulado "La euforia ha remitido" hablaba de los sentimientos de rechazo que empezaban a experimentarse frente a los refugiados de la DDR ${ }^{38}$. $\mathrm{Y}$, al fin, en el número del día 17, una semana después de los acontecimientos, Die Zeit trataba con toda exuberancia de medios (reportajes, crónicas, informes y fotografías) la gran noticia. Pero en portada, como era de esperar, el semanario de Hamburgo se sumaba al coro de los que veian libertad más que unidad, y aun así con interrogante, al tomar como titular del artículo de fondo una frase de Fidelio: "Oh libertad, ¿retornas tú de nuevo?". "Reina un estado emocional exaltado y cordial», decía su autor Theo Sommer, y «algunos, no muchos, creen que ahora mismo, sin rodeos y rotundamente, debe apuntarse hacia la reunificación de los dos estados alemanes". Pero en Alemania occidental, prosigue el periodista, «no hay explosión nacionalista, ni impacientes exigencias de imponer la cuestión alemana en la agenda de la política mundial", incluso aquellos que no se resignan a la división "saben que la unidad, en el mejor de los casos, solo se obtendrá al final de un largo desarrollo que no ha hecho más que empezar». El fallo de la argumentación, teniendo en cuenta lo que vino a continuación, estriba en que Sommer la extiende también a la otra Alemania, a pesar de alguna reserva de paso: "Tampoco en la DDR la alegría del reencuentro se ha transformado en acuciantes exigencias de reunificación", apenas si este tema figura como slogan en las pancartas de los manifestantes, prosigue, y está ausente de los documentos de la oposición, que a veces defienden expresamente la existencia de dos estados separados. La salvedad final («mag sein daß...") por lo que hace a la "masa de los ciudadanos de la DDR", donde

37 En el primer editorial del dia 11, titulado “Die Welt am Tag danach», la caida del muro es calificada tal como antes dijimos de «politisches Naturereignis über Nacht», el segundo, firmado por Friedrich Karl Fromme es el titulado "Die Mauer-ein Denkmal?".

38 Helmut SCHMIDT, "Ein Aufstand gegen Zwang und Lüge», R. Kirbach, "Die Euphorie ist abgeklungen», Die Zeit, 10.11.1989. 
quizá germinen ideas distintas, no afecta al centro de una argumentación que patentiza, aqui como en otros casos, la ignorancia de lo que se estaba gestando a finales de $1989^{39}$.

Tras la caída del Muro el nuevo gobierno de Hans Modrow, el alcalde reformista de Dresde, aunque liberado del lastre que significaba Krenz, el sucesor de Honecker, se enfrentaba con una situación políticamente cada vez más complicada y económicamente catastrófica. Los reporteros de la prensa occidental, a estas alturas desplazándose libremente por el interior de la DDR, informaban de cosas asombrosas: el pueblo comenzaba a ajustar cuentas a los espías de la Stasi, los comités de ciudadanos salvaban de la destrucción documentos comprometedores para el régimen, e incluso se veían obligados a enfrentarse a intentos de linchamiento de antiguos policias, y se denunciaban públicamente las corrupciones del régimen. En las manifestaciones en las grandes ciudades comienzan a predominar sloganes de reunificación, en Leipzig se pasa de gritar "Wir sind das Volk» a gritar "Wir sind ein Volk». Sin embargo, en este periodo de tiempo se advierte un acuerdo entre los dos gobiernos para retardar en todo caso un proceso que amenaza con desbocarse. De esta manera, si el 17 de noviembre Hans Modrow ofrecia a Bonn una "Vertragsgemeinschaft", una comunidad contractual, el 28 del mismo mes el canciller occidental Helmut Kohl le respondía, presentando al Bundestag un plan de diez puntos que preveía, una vez que el régimen de la DDR se democratizase, una fase confederal de los estados alemanes como preámbulo de una unidad $\sin$ plazo fijo $^{40}$.

La prensa en general se acomodó a la cadencia que marcaron los políticos. Mientras que los reportajes de las páginas interiores o de los suplementos dominicales dieron cuenta de la experiencia vivida, de las exigencias de reunificación en la DDR, los editoriales de primera página, cada uno en su línea, advertían contra ilusiones excesivas o pasos precipitados.

A comienzos de diciembre el FAZ juzgaba "risible» la declaración de Miterrand y Gorbachov en Kiew diciendo que "la cuestión alemana no está en el orden del día", pero a continuación afirmaba que nadie había dicho que la reunificación fuera cosa inmediata, tal como muestra, dice el periódico, el plan de diez puntos de Kohl, que se había librado mucho de marcar plazos. Seis días después, ante las ultimas manifestaciones en Leipzig, "el sismógrafo del terremoto político de la DDR", aunque la unidad

Theo Sommer, “O Freiheit! kehrest Du zurück?», Die Zeit, 17.11.1989.

46. En privado Kohl daba una duración de unos diez años a la fase previa a la reunificación. "the unity despite the Germanys" dice McAdams, o.cit., p.204 y ss. 
estatal no sea "ad calendas graecas" (literalmente "an Sankt Nimmerlein»), tampoco esto significaba que pudiera "hacerse de un día para otro, se necesita paciencia» ${ }^{41}$. El Frankfurter Rundschau fue más allá, pues contra los tonos chauvinistas o los alocamientos por la reunificación, advertía que la unidad, "si alguna vez llega [sic], no lo hará de la noche a la mañana a pesar de la velocidad con la que se desarrollan los procesos en la Alemania oriental, sino al final de un largo y difícil proceso". Unos dias más tarde el mismo periódico no dudaba incluso en apelar al testimonio del mismo canciller en contra de algunos de sus congéneres: "hace unos días Kohl ha llegado a reírse de la gente que cree que la reunificación ya se ha preparado para mañana por la tarde"... ${ }^{42}$.

El día 19 de diciembre Kohl y Modrow se encuentraron en Dresde, "a ambos les cuesta trabajo imponerse frente a las llamadas a una reunificación inmediata de los manifestantes", tal como informaba el corresponsal del Frankfurter Rundschau en aquella ciudad, mientras que el corresponsal del FAZ hablaba de la "impaciencia que crece y las expectativas de los manifestantes» ${ }^{43}$. A pesar de todo Kohl, terminó asegurando a Modrow la pervivencia de la DDR durante la anunciada etapa de la confederación entre los dos estados, cosa más fácil de hacer dado que ya para entonces el jefe de gobierno oriental habia anunciado las primeras elecciones libres de la DDR. Todavía el 30 de diciembre el FAZ albergó en sus páginas un sabio artículo de un catedrático de filosofía del derecho sobre "las estaciones en el camino de la confederación a la federación", donde en todo caso no dejaba de advertir contra "planes de reunificación excesivamente apresurados" ${ }^{44}$

Pero la unidad iba a llegar, y mas rápidamente de lo que nadie creía y aun se resistía a creer, tal como mostraría una prolongación de nuestro análisis de la prensa durante el periodo que concluye el 9 de octubre de 1990 , el día de la reunificación alemana. Todavía a finales de 1989, tras

41 "Rechte und Pflichten", FAZ, 8.12.1989; "Für die Einheit auf die Strasse", Frit Ullrich Fack, FAZ, 14.12,1989.

4. Kar-Heinz BauM, "Konkursmasse oder Versuchskanichen?", Frankfurter Rundschau,13.12.1989; “Einmischung”, Hans-Herbert Gaebel, Frankfurter Rundschau, 15.12.1989.

43 Eghard MORBITz, "Helmut und Hans, macht's Deutschland ganz", Kohl und Modrow hatten Mühe, sich gegen die Rufe der Dresdner nach baldiger Einheit durchzusetzen", en Frankfurter Rundschau , 20.12.1989; Monika Zimmermann, "Die Ungeduld der Demonstranten wächst. Erwartungen in Dresden". FAZ, 20.12.1989. Merk| dice que ya desde la manifestación de Leipzig del 22 de noviembre (Wir sind ein Volk!), Kohl y Modrow habian decidido proseguir con sus planes, ignorando el apremio unificador de los manifestantes, o.cit., p.123-124.

44 Prof Dr. Waldemar SCHRECKENBERG, "Eine Staatgemeinschatf in Deutschland", FAZ, 30.12.1989. 
constatar que en Dresde se habían confrontado dos perspectivas muy distintas sobre el porvenir de Alemania, el Frankfurter Rundschau concluía en su editorial que "solo la Historia nos mostrará lo que vaya a venir» ${ }^{45}$. Ciertamente el diario de Frankfurt, de haber sabido que hasta la reunificación faltaban tan solo nueve meses, habría apelado al prosaico calendario en vez de a una tan alta instancia como la Historia.

Hablando de la historia del tiempo presente, René Rémond ha dicho que tal tipo de historia nos recuerda la importancia de la contingencia y el acontecimiento, de que la historia está hecha de sorpresas, más de sorpresas que de astucias ${ }^{46}$. En este sentido la prensa, como hemos dicho al principio, es algo más que una crónica de hechos. La prensa nos puede mostrar, primero, los acontecimientos con «el vocabulario con que se pueden expresar los problemas personales, un drama o un dolor del hombre común y corriente...", en este caso, los problemas del pueblo de la DDR, los dramas y dolores de masas de refugiados, la experiencia en suma, adelantándose así a los futuros historiadores de lo cotidiano ${ }^{47}$.

En segundo lugar, la prensa no solo confirma que hay sorpresas en la historia del día a día, a menudo sacrificadas en aras de la posterior racionalización del pasado, sino que además la gente a veces se resiste a aceptarlas casi hasta el final, como parecería que sucede en el caso de la reunificación alemana.

Y además de la sorpresa, el temor. Nuestra lectura de los textos necesitaria para ser completa haber incorporado el temor, el temor a la reacción de los aliados y de la Unión Soviética de entonces, sentida como la amenaza de siempre, pues nadie presentía el ocaso de Rusia como gran potencia ${ }^{48}$. Y por ultimo, la esperanza, "das Prinzip Hoffnung", que diría Ernst Bloch. En buena medida las resistencias a aceptar una unificación, o

\footnotetext{
45 Karl-Heinz BaUM, "Die ersten Schritte", Frankfurter Rundschau, 20.12.1989.

46 «Quelques questions de portée générale», en Ecrire... o.cit., p. 29-44, p.33.

47 El entrecomillado de un texto del periodista polaco R. KAPUSCINSKI, que entero dice así: "...la lengua de la omnipresente política puede eliminar de los medios de comunicación -lo que es peor- de nuestra memoria el vocabulario con que se expresan problemas personales. un drama o un dolor del hombre común y corriente...". El Imperio, Barcelona, 1994, la ed. original es de 1993, p.328. Es significativo que en el caso alemán los historiadores de lo cotidiano y de la "Oral History" terminaron incorporándose a los media, completando la labor realizada por los reporteros; asi el director del Kulturwissenschaftliches Institut de Essen, Lutz Niethammer, trató de la evolución de la DDR en dos largos artículos publicados en el Frankfurter Rundschau del 6 y 8 de enero de 1990, titulados «Ensayo de una percepción histórica de los acontecimientos en curso en la DDR", Versuch einer historischen Wahrnehmung der laufenden Ereignisse in der DDR.

48 Por remitimos aqui otra vez a la sorpresa y a un periodista, Kapuscinski recuerda que no hubo ningún especialista que predijese la crisis final de la Unión Soviética en los años ochenta, o.cit., p. 334.
} 
por lo menos una reunificación prematura, en periódicos como el Frankfurter Rundschau se debían a la esperanza de un "nuevo socialismo», de una DDR reformada. "El paisaje deseado", por expresarnos con la terminología del filósofo de Leipzig, era un "Sozialismus mit menschliches Angesicht", un socialismo con rostro humano, al que no seria insensible a la larga la República federal ${ }^{49}$. Pero el 3 de octubre de 1990 la realidad final respondió más a la esperanza de los editorialistas del Frankfurter Allgemeine Zeitung que a la de los del Frankfurter Rundschau o incluso a los de Die Zeit: «El dia de la unificación ya no hubo dudas: la república federal seguiría siendo lo que había sido, solo que más grande» ${ }^{50}$.

49 Por ejemplo el editorial de K-H-Baum, "Ost -Berliner Perspektiven», Frankfurter Rundschau, 4.10.1989 al que pertenece el entrecomillado.

so Dietrich StaRITZ, o.cit., p. 407 